mediastudies.press • Social Media \& the Self: An Open Reader

\title{
How Smartphone Cameras \\ Changed the Way We Document Our Lives
}

Jane C. Hu

Published on: Dec 30, 2019

DOI: $10.32376 / 3 f 8575 c b . b 27 e 15 c f$

License: Creative Commons Attribution-NonCommercial 4.0 International License (CC-BYNC 4.0). 
AS THE DECADE comes to a close, social media is packed with nostalgic memes marking the end of the decade. On Twitter, people are humblebragging about their biggest personal accomplishments. (Mine is a tie between meeting a cat named Larry David and finally going to a Guy Fieri restaurant.) And predictably, on Instagram, people are posting side-by-side photos of their 2009 selves and their current selves.

Search the Instagram hashtag \#2009to2019 or \#10yearchallenge and you'll notice bangs are out and flannel is in. But there are two basic changes related to technology that are easy to miss. The first is unsurprising: Image quality has gotten much better. The second showcases how our photo taking style has changed. While most people's 2009 photos are obviously taken by someone else-full-body shots from a distance, often containing little bits of forearm or cheek that reveal friends or family cropped out -most people's current photos are mirror selfies where their smartphone is visible, or a flattering front-facing camera snap. Just as video killed the radio star, the smartphone has largely replaced the stand-alone camera....

continue reading

\section{OUTBOUND LINK}

"How Smartphone Cameras Changed the Way We Document Our Lives" (Jane C. $\mathrm{Hu}$, Slate, December 30, 2019)

FREE ACCESS 